\title{
Biomimetic interfacial interpenetrating polymer networks control neural stem cell behavior
}

\author{
Krishanu Saha, ${ }^{1}$ Elizabeth F. Irwin, ${ }^{2}$ Julia Kozhukh, ${ }^{1}$ David V. Schaffer, ${ }^{1,3}$ Kevin E. Healy ${ }^{2,4}$ \\ ${ }^{1}$ Department of Chemical Engineering, University of California at Berkeley, Berkeley, California \\ ${ }^{2}$ Department of Bioengineering, University of California at Berkeley, Berkeley, California \\ ${ }^{3}$ The Helen Wills Neuroscience Institute, University of California at Berkeley, Berkeley, California \\ ${ }^{4}$ Department of Materials Science and Engineering, University of California at Berkeley, Berkeley, California
}

Received 7 April 2006; revised 21 June 2006; accepted 31 July 2006

Published online 18 January 2007 in Wiley InterScience (www.interscience.wiley.com). DOI: 10.1002/jbm.a.30986

\begin{abstract}
Highly-regulated signals surrounding stem cells, such as growth factors at specific concentrations and matrix mechanical stiffness, have been implicated in modulating stem cell proliferation and maturation. However, tight control of proliferation and lineage commitment signals is rarely achieved during growth outside the body, since the spectrum of biochemical and mechanical signals that govern stem cell renewal and maturation are not fully understood. Therefore, stem cell control can potentially be enhanced through the development of material platforms that more precisely orchestrate signal presentation to stem cells. Using a biomimetic interfacial interpenetrating polymer network (IPN), we define a robust synthetic and highly-defined platform for the culture of adult neural stem cells. IPNs modi-
\end{abstract}

fied with two cell-binding ligands, CGGNGEPRGDTYRAY from bone sialoprotein [bsp-RGD(15)] and CSRARKQAASIKVAVSADR from laminin [lam-IKVAV(19)], were assayed for their ability to regulate self-renewal and differentiation in a dose-dependent manner. IPNs with $>5.3 \mathrm{pmol} / \mathrm{cm}^{2} \mathrm{bsp}-$ $\mathrm{RGD}(15)$ supported both self-renewal and differentiation, whereas IPNs with lam-IKVAV(19) failed to support stem cell adhesion and did not influence differentiation. The IPN platform is highly tunable to probe stem cell signal transduction mechanisms and to control stem cell behavior in vitro. (C) 2007 Wiley Periodicals, Inc. J Biomed Mater Res 81A: 240-249, 2007

Key words: hydrogel; RGD; laminin; IKVAV; $\alpha_{\mathrm{v}} \beta_{3}$ integrin

\section{INTRODUCTION}

For stem cells to function therapeutically in the body, stringent temporal and spatial requirements on self-renewal, differentiation, and migration must be met. ${ }^{1}$ However, such control can potentially be compromised by heterogeneity in harvested cell populations, artifacts introduced by ex vivo culture (e.g., ani-

Correspondence to: D.V. Schaffer; e-mail: schaffer@cchem. berkeley.edu or K.E. Healy; e-mail: kehealy@berkeley.edu

Contract grant sponsor: National Institute of Health; contract grant number: AR43187-07

Contract grant sponsor: Berkeley Futures Grant

Contract grant sponsor: NINDS grants; contract grant number: NS048248

Contract grant sponsor: National Science Foundation Graduate Fellowship (to KS)

Contract grant sponsor: Whitaker Graduate Fellowship Award

Contract grant sponsor: Graduate Research and Education in Adaptive bio-Technology (GREAT) Training Program, UC Systemwide Biotechnology Research and Education Program; contract grant number: 2005-280

(C) 2007 Wiley Periodicals, Inc. mal product impurities and genetic or epigenetic instability), or harsh microenvironments at the implantation site. $^{2}$ A rational strategy to address these problems is to tailor the cellular microenvironment during harvest, culture, and/or implantation to enhance control over stem cell function. Employing a synthetic materials approach, we engineered a system to present well-characterized signals to stem cells. This tunable and modular microenvironment enables control over stem cell self-renewal and differentiation signals in vitro, and can enable quantitative analysis of mechanisms that regulate these processes in vitro and in vivo.

Considerable work on controlling the microenvironment around stem cells has focused on defining soluble media components for many stem cell lines ${ }^{3-5}$; however, stem cells are most often propagated on surfaces that contain animal-derived components with ambiguous signaling properties. Typical culture surfaces consist of poly(styrene) with either a passively adsorbed animal-derived extracellular matrix (ECM) protein or a "feeder" layer of mammalian cells. Animal-derived ECM or protein molecules, in either twoor three-dimensional supports, likely contain variable 
splice and glycoforms, offer limited micro- and nanoscale control of solid-phase signaling, and otherwise present problems for therapeutic application. ${ }^{6}$ In particular, the ECM component laminin is a large, posttranslationally modified protein $(850 \mathrm{kDa})$ that is difficult to produce via recombinant expression systems and thus is commonly purified from mammalian cell lines. In addition, human laminin, such as for human embryonic stem cell propagation, is particularly problematic due to significant source variability. Finally, the functions of different cell-binding motifs of laminin and other ECM components have only been partially characterized in select cell lines and are largely unknown for many stem cell lines.

Multipotent neural stem cells (NSCs) derived from the adult hippocampus are potentially attractive for neuroregeneration therapies. ${ }^{1,6-8}$ Natural ECM molecules such as laminin, collagen, and vitronectin modulate NSC growth rates in vitro (data not shown) and likely engage various integrin adhesion receptors. Integrin signaling has previously been implicated in the survival, proliferation, and differentiation mechanisms of fetal and postnatal neural progenitors. ${ }^{9}$ In vitro, NSCs are often propagated in adherent culture on surfaces coated with laminin- $1,{ }^{10}$ which engages a number of integrin receptors, including $\alpha_{\mathrm{v}} \beta_{3}, \alpha_{1} \beta_{1}$, $\alpha_{\mathrm{IIb}} \beta_{3}, \alpha_{2} \beta_{1}, \alpha_{6} \beta_{1}, \alpha_{7} \beta_{1}$, and $\alpha_{6} \beta_{4}$, and other unknown cellular receptors. ${ }^{11}$ Rather than using a ligand that engages multiple cellular receptors with numerous, undetermined downstream signal transducers, this initial attempt to control NSC behavior employed a single well-characterized ECM motif common to laminin, vitronectin, and fibronectin: an Arg-Gly-Asp (RGD) adhesion motif. This motif was grafted onto a synthetic interpenetrating polymer network (IPN) to create a highly mechanically and chemically defined NSC culturing environment. Additionally, we explored the function of a laminin motif, lam-IKVAV(19), since both two- and three-dimensional presentation of various laminin domains such as IKVAV influence neurite extension of adult whole hippocampal explants ${ }^{12,13}$ and fetal neural progenitor differentiation. ${ }^{14}$ Such precise control of particular ECM motifs is not possible in traditional cell culture materials, and our results on peptide-modified IPNs has implications for both basic stem cell biology and therapeutic efforts.

\section{MATERIALS AND METHODS}

\section{Materials}

Acrylamide (AAm), poly(ethylene glycol) 1000 monomethyl ether monomethacrylate (pEG1000MA), acrylic acid (AAc), and N,N'-methylenebis(acrylamide) (BIS; Chemzymes, ultrapure grade) were purchased from Polysciences (Warrington, PA). N-hydroxysulfosuccinimide (sulfo-NHS),
2-(N-morpholino) ethanesulfonic acid, $0.9 \%$ sodium chloride buffer (MES; "BupH MES Buffered Saline Pack"), and sulfosuccinimidyl 4-(N-maleimidomethyl) cyclohexane-1carboxylate (sulfo-SMCC) were acquired from Pierce (Rockford, IL). [3-(3,4-Dimethyl-9-oxo-9H-thioxanthen-2-yloxy)2-hydroxypropyl] trimethylammonium chloride (QTX) was obtained from Aldrich (Milwaukee, WI). Allyltrichlorosilane (ATC) was obtained from Gelest (Morrisville, PA). Diamino-poly(ethylene glycol) [PEG($\left(\mathrm{NH}_{2}\right)_{2} ; 3400 \mathrm{~g} / \mathrm{mol}$, chromatographically pure] was purchased from Nektar (Huntsville, AL). All water used in this study was ultrapure ASTM Type I reagent grade water $(18.2 \mathrm{M} \Omega \mathrm{cm}$, pyrogen free, endotoxin $<0.03 \mathrm{EU} / \mathrm{mL}$ ). RGD and RGE peptides were synthesized by American Peptide (Sunnyvale, CA) and characterized using mass spectrometry and high-performance liquid chromatography (purity $>95 \%$ ). RGD and RGE peptides were based on the integrin-binding sequence from rat bone sialoprotein: bsp-RGD(15) peptide, Acetyl-CGGNGEPRGDTYRAY- $\mathrm{NH}_{2}$; bsp-RGE(15) peptide, Acetyl-CGGNGEPRGETYRAY- $\mathrm{NH}_{2} ;$ bsp-RGD(15)-FI TC, Acetyl-CGGNGEPRGDTYRAYK(FITC)GG- $\mathrm{NH}_{2}$ [note that bsp-RGD(15) peptide is the same as l-RGD, as described previously]. ${ }^{15,16}$ The lam-IKVAV(19) peptide was purchased from Sigma-Aldrich (St. Louis, MO) and was chosen from the laminin A chain (amino acids 2091-2108, i.e., laminin peptide PA22-2): CSRARKQAASIKVAVSADR. Poly(styrene) 8-well strips (Costar \#2580), 35-mm tissue culture poly(styrene) dishes, and paraformaldehyde (reagent grade) were purchased from Fisher Scientific (Santa Clara, CA). Dulbecco's phosphate-buffered saline (DPBS, without calcium chloride, without magnesium chloride, $\mathrm{pH}=7.2 \pm 0.1$ ), Dulbecco's modified eagle medium (F-12/DMEM, high glucose, with l-glutamine, with pyridoxine hydrochloride, without sodium pyruvate), N-2 supplement, 4',6-diamidino-2-phenylindole (DAPI), polyornithine, natural mouse laminin, and recombinant basic fibroblast growth factor-2 (bFGF) were purchased from Invitrogen (Carlsbad, CA). Retinoic acid and forskolin were both obtained from BioMol (Plymouth Meeting, PA). For immunofluorescent staining, primary antibodies of mouse anti-nestin were purchased from Becton Dickinson (Franklin Lakes, New Jersey), mouse anti-microtubule associated protein 2ab (Map2ab) from Sigma-Aldrich (St. Louis, MO), and guinea pig anti-glial fibrillary acidic protein (GFAP) from Advanced Immunochemical (Long Beach, CA). Alexa fluorochrome-conjugated secondary antibodies, CyQUANT dye, and Sybergreen were purchased from Molecular Probes (Eugene, Oregon). For characterization by quartz crystal microbalance with dissipation monitoring (QCM-D), quartz sensor crystals were purchased from Q-sense (Newport Beach, CA). All other chemicals used were reagent grade and used as purchased without further purification. All glassware was cleaned as described previously. ${ }^{17}$

\section{Laminin cell culture surfaces}

Positive control surfaces were coated with polyornithine and saturated with mouse laminin-1 (Invitrogen, from the Engelbreth-Holm-Swarm (EHS) sarcoma) as described in the literature. ${ }^{8}$ Briefly, polyornithine $(10 \mu \mathrm{g} / \mathrm{mL}$ in water) was added to cover each poly(styrene) culture well and incubated overnight at room temperature. Wells were then 
rinsed twice with sterile water, and laminin $(\sim 5 \mu \mathrm{g} / \mathrm{mL}$ in DPBS) was added to cover each well. After incubation overnight at $37^{\circ} \mathrm{C}$, wells were frozen at $-20^{\circ} \mathrm{C}$. Wells were thawed at $37^{\circ} \mathrm{C}$ immediately before use.

\section{IPN cell culture surfaces}

Polymerization and conjugation details can be found elsewhere, ${ }^{16}$ but are described briefly below. All reactions were carried out at room temperature unless otherwise stated. Poly(styrene) (PS) surfaces were cleaned by submersion in a $5 \mathrm{M} \mathrm{NaOH}$ ethanol/ultrapure water (UPW) solution (v/v, $70 / 30$ ) for $1 \mathrm{~h}$, rinsed, and sonicated (30 min; Branson model $5510,40 \mathrm{kHz}, 469 \mathrm{~W}, 117 \mathrm{~V})$ in UPW. After cleaning, the samples were dried $\left(\mathrm{N}_{2}\right)$ and activated with an oxygen plasma. The IPN was then grafted to PS using a two-step sequential photopolymerization similar to previously published protocols. After an 8-10 min adsorption of AAm solution $(0.1485 \mathrm{~g} / \mathrm{mL}$ AAm, $0.0015 \mathrm{~g} / \mathrm{mL}$ BIS, $0.01 \mathrm{~g} / \mathrm{mL}$ QTX, $0.03 \mathrm{~mL} / \mathrm{mL}$ isopropyl alcohol, $0.97 \mathrm{~mL} / \mathrm{mL} \mathrm{UPW),} \mathrm{the}$ samples underwent photoinitiated free radical polymerization using a transilluminator table (model TFL-40; Ultra-Violet Products, Upland, CA) for $4.5 \mathrm{~min}$. The power of the table was measured at $2.3 \mathrm{~mW} / \mathrm{cm}^{2}$ using a radiometer (International Light, MA), with a 352-377 $\mathrm{nm}$ band-pass filter. Following polymerization, excess homopolymer was aspirated and the samples were placed in UPW (>10 $\mathrm{min})$, rinsed, and sonicated (UPW, $5 \mathrm{~min}$ ). After sonication, the samples were rinsed (UPW) and dried $\left(\mathrm{N}_{2}\right)$. An IPN of p(AAm-co-EG/AAc) was formed [Fig. 1(a)] after an 8$10 \mathrm{~min}$ exposure of the pAAm layer to PEG/AAc solution $(0.0200 \mathrm{~g} / \mathrm{mL}$ PEG, $0.0100 \mathrm{~g} / \mathrm{mL}$ BIS, $0.005 \mathrm{~g} / \mathrm{mL}$ QTX, $0.0162 \mathrm{~mL} / \mathrm{mL}$ AAc, $0.5 \mathrm{~mL} / \mathrm{mL}$ isopropyl alcohol, $0.5 \mathrm{~mL} /$ $\mathrm{mL}$ UPW) and subsequent photoinitiated polymerization for $6 \mathrm{~min}$. Following the formation of the IPN, the samples were equilibrated with buffer ( $>30 \mathrm{~min}, 0.5 \mathrm{M}$ MES, $\mathrm{pH} 7$ ). To functionalize the IPN with biological ligands, $3400 M_{\mathrm{w}}$ $\operatorname{PEG}\left(\mathrm{NH}_{2}\right)_{2}$ spacer chains were grafted to the AAc sites via a carbodiimide reaction [60 min, 0.5M MES, pH 7, $0.150 \mathrm{~g} / \mathrm{mL}$ PEG $\left(\mathrm{NH}_{2}\right)_{2}, 0.005 \mathrm{~g} / \mathrm{mL}$ EDC, $0.0025 \mathrm{~g} / \mathrm{mL}$ sulfo-NHS]. After the reaction, the solution was aspirated and the samples were rinsed twice with 0.1M MES buffer ( $\mathrm{pH}$ 7.0) followed by twice rinse with $50 \mathrm{mM}$ sodium borate buffer ( $\mathrm{pH}$ 7.5). To couple bioactive molecules to the PEG( $\left(\mathrm{NH}_{2}\right)_{2}$-modified IPN, the heterobifunctional cross-linker, sulfo-SMCC, was reacted with the free amine on the $\operatorname{PEG}\left(\mathrm{NH}_{2}\right)_{2}$ chains $(0.0005 \mathrm{~g} / \mathrm{mL}$ sulfo-SMCC, $\mathrm{pH} 7.5$, borate buffer). The solution was then aspirated, and the samples were rinsed twice with borate buffer followed by twice rinse with peptide-coupling buffer (0.1M sodium phosphate, $\mathrm{pH}$ 6.6). Finally, the peptide [bsp-RGD(15), bsp-RGE(15), bsp-RGD(15)-FITC, or lam-IKVAV(19)] was coupled $(0-20 \mu \mathrm{M})$ to the maleimide (sulfo-SMCC) at the peptide N-terminal free thiol. Following the reaction, the solution was aspirated and the samples were rinsed 4-5 times with coupling buffer, sonicated (UPW, $5 \mathrm{~min}$ ), rinsed (UPW), and dried $\left(\mathrm{N}_{2}\right)$.

The surfaces of the QCMD sensor crystals were modified for characterization with an IPN of $\mathrm{p}$ (AAm-co-EG/AAc) as described above, except that a unsaturated silane was chemisorbed to the surface prior to the polymerization step as described previously. ${ }^{17}$ Briefly, sensor crystals were coated with $200 \mathrm{~nm}$ of silicon/silicon dioxide $\left(\mathrm{Si} / \mathrm{SiO}_{2}\right)$, and an unsaturated organosilane, ATC, was grafted onto the crystals by soaking them in a $1.25 \%(\mathrm{v} / \mathrm{v})$ solution of ATC in anhydrous toluene (prepared in a nitrogen glovebox) for $5 \mathrm{~min}$. The sensor crystals were baked for $30 \mathrm{~min}$ at $125^{\circ} \mathrm{C}$, and the IPN synthesis of $\mathrm{p}$ (AAm-co-EG/AAc) proceeded as described above.

\section{Characterization of IPN surfaces}

A QCM-D D300 (Q-sense) was used in this study, as described in detail elsewhere. ${ }^{17}$ Briefly, in a QCM-D experiment, four separate resonant frequencies (overtones, $n$ ) were used to drive oscillation of the shear wave through the crystal: $\sim 5 \mathrm{MHz}$ (fundamental overtone, $n=1), \sim 15 \mathrm{MHz}(n=$ $3), \sim 25 \mathrm{MHz}(n=5)$, and $\sim 35 \mathrm{MHz}(n=7)$. The applied voltage for each resonant frequency was sequentially pulsed across the sensor crystal, allowing shear wave dissipation with the simultaneous measurement of the absolute dissipation $(D)$ and the absolute resonant frequency $(f)$ of the crystal for all four overtones. All measurements were taken at $37^{\circ} \mathrm{C}$. The $f$ and $D$ values were recorded for the crystals before and after ex situ modification, both dry and in DPBS. Dry thickness was calculated via the Sauerbrey relationship, $\Delta M=-C \Delta f / n$, where $\Delta M$ is the total change in mass of a rigid, elastic adlayer, $C$ is a constant $\left(17.7 \mathrm{ng} / \mathrm{cm}^{2} \mathrm{~Hz}\right)$ based on the physical properties of the quartz crystal, and $n$ was the overtone number. The IPN surfaces were swollen in DPBS (sample size of 3). Degassed DPBS was introduced into the measurement chamber, and the chamber was sealed during the 16-h swelling period. For protein adsorption studies, proliferation or differentiation media (see neural stem cell culture) was introduced for $1 \mathrm{~h}$, and then rinsed twice with DPBS for $5 \mathrm{~min}$. Peptide density and degradation analysis of such surfaces have been characterized elsewhere. ${ }^{18} \mathrm{X}$-ray photoelectron spectra (XPS) were recorded using a PHI 5400 instrument (Physical Electronics, Chanhassen, MN), with a nonmonochromatic $\mathrm{Mg}$ anode as the $\mathrm{X}$-ray source at a takeoff angle of $55^{\circ}$, using the same method as described elsewhere. $^{16,17}$

\section{Neural stem cell culture}

Neural stem cells were isolated from the hippocampi of adult female Fischer 344 rats as previously described. ${ }^{8}$ Cells $\left(600-30,000\right.$ cells $\left./ \mathrm{cm}^{2}\right)$ were seeded onto peptide-modified and laminin-modified culture wells and incubated $\left(37^{\circ} \mathrm{C}\right.$, $5 \% \mathrm{CO}_{2}$ ) in serum-free media consisting of DMEM/Hams F12 medium with $\mathrm{N}-2$ supplement. These media conditions were supplemented with various soluble factors to modulate cell behavior: $20 \mathrm{ng} / \mathrm{mL}$ bFGF for cell proliferation or $1 \mu M$ retinoic acid with $5 \mu M$ forskolin for neuronal differentiation. Wells were rinsed every $48 \mathrm{~h}$ with fresh media.

\section{Neural stem cell assays}

Cells were seeded at $10^{2}-10^{5}$ cells $/ \mathrm{cm}^{2}$ on various surfaces and grown for 3-6 days, and cell number was determined using the CyQUANT (Molecular Probes, Eugene, OR) assay following the manufacturer's instructions. For im- 
a

\section{bsp-RGD(15) peptide: \\ lam-IKVAV(19) peptide: \\ CGGNGEPRGDTYRAY CSRARKQAAS $\underline{\text { IKVAVSADR }}$}<smiles>CCCCC(C)(N)OCC(C)N</smiles><smiles>NS(=O)(=O)[C@H]1C[C@@H](O)[C@@H](O)N1O</smiles><smiles>COCC(C)(C)OC(=O)C(C)C</smiles><smiles>O=C(O)/C=C\CCCCCO</smiles><smiles>C/C=C\C(N)=O</smiles>

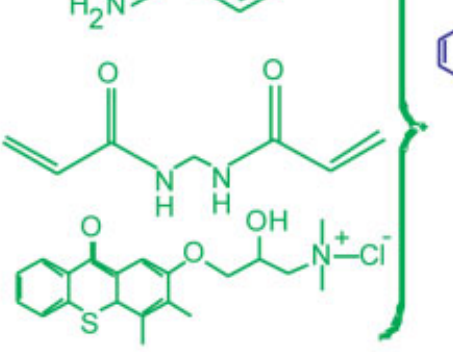
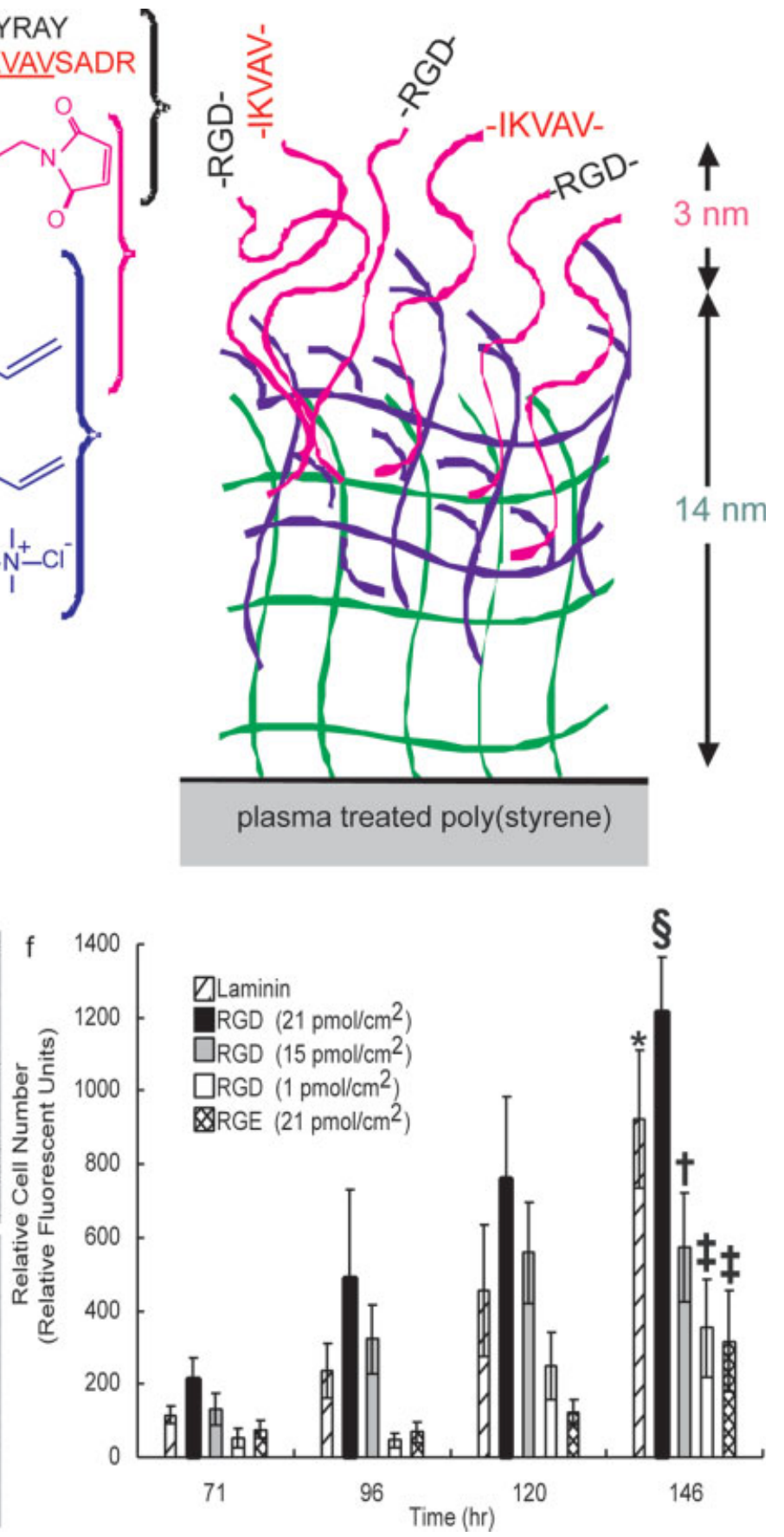

Figure 1. Synthetic IPNs with RGD peptides support attachment, spreading, and proliferation of neural stem cells in a dose-dependent manner. (a) Schematic representation of IPN synthesis (not to scale). Sequential polymerization steps create an IPN that is swollen in aqueous media and conjugated with bioactive peptides. (b-e) Phase-contrast images of neural stem cells grown on top of IPNs or laminin-1 in proliferating media conditions (1.2 nM basic fibroblast growth factor); (f) Growth curves for proliferation of neural stem cells as assayed by a total nucleic acid stain. Data represent mean \pm standard deviation of 3-5 samples. Surfaces not in the same group $(*, \S, \dagger$, or $\$)$ were statistically different from one another $(p<0.05$; ANOVA between groups with Tukey-Kramer Honestly Significant Difference post hoc test). [Color figure can be viewed in the online issue, which is available at www.interscience.wiley.com.]

munofluorescent staining, cells on days 1-14 were fixed with $4 \%$ paraformaldehyde DPBS and stained with primary antibodies of mouse anti-nestin (1:1,000 dilution), mouse anti-microtubule associated protein 2ab (Map2ab) (1:250), and guinea pig anti-glial fibrillary acidic protein $(1: 1,000)$.
Detection of primary antibodies was performed with Alexa fluorochrome-conjugated secondary antibodies at a dilution of 1:250. Nuclei were stained with the DNA dyes SYBR Green and DAPI. Images were collected on an Olympus IX-50 microscope and a Zeiss META 510 laser scanning 
confocal microscope. Quantitative real-time PCR (qRT-PCR) was used as a complementary technique to accurately quantify specific cDNA concentrations in various cDNA samples from cells grown on IPNs and laminin (using a Bio-Rad Laboratories iCycler 4). We have recently developed this combination of qRT-PCR and immunofluorescent staining to assay the phenotype of stem cells. ${ }^{19}$ GFAP expression levels were quantified as a marker for astrocytic differentiation of the progenitor cells. $\beta$-Tubulin-III was used as a marker for neurons, and nestin was used as a marker for NSCs. Ribosomal $18 \mathrm{~S}$ was employed to normalize the various samples for differences in the starting amounts of cDNA used in each sample. The utilized primers and TAQMAN probes are listed as follows in the following format (marker, 5'-primer, $3^{\prime}$ primer, hybridization TAQMAN oligo): (GFAP, GACCTG CGACCTTGAGTCCT, TCTCCTCCTTGAGGCTTTGG, TCC TTGGAGAGGCAAATGCGC), ( $\beta$-Tubulin-III, GCATGGATG AGATGGAGTTCACC, CGACTCCTCGTCGTCATCTTCATAC, TGAACGACCTGGTGTCTGAG) (nestin, GAGCTCTCTGGG CAAGTGGA, CTCCCACCGCTGTTGATTTC, AGGACAG-TCAGCAGTGCCTGCA), and (18S, GTAACCCGTTGAACCC CATTC, CCATCCAATCGGTAGTAGCGA, AAGTGCGGG TCATAAGCTTGCG). Standards for performing qRT-PCR were pPCR4-TOPO plasmids (Invitrogen, Carlsbad, CA) containing the amplicon of interest as an insert. The plasmids were linearized by restriction digest and quantified by absorbance, and 10-fold serial dilutions from 1 to $10^{-9} \mathrm{ng}$ were prepared to generate a standard curve. All samples were conducted in duplicate.

\section{RESULTS AND DISCUSSION}

Peptide-modified IPNs [Fig. 1(a)] were used to examine the ability of oligopeptides derived from the active domains of adhesion proteins found within ECMs (e.g., laminin and bone sialoprotein) to regulate adult NSC self-renewal and differentiation. The IPNs were synthesized from acrylamide (AAm), poly(ethylene glycol) 1000 monomethyl ether monomethacrylate (pEG1000MA), and acrylic acid (AAc) monomers [Fig. 1(a)]. These monomers were chosen to minimize protein adsorption and prevent any nonspecific substrate signaling to stem cells, such that defined biochemical signals could be subsequently introduced onto the surface. After characterizing the IPN, we show that an integrin-binding ligand, bsp-RGD(15), within the IPN culturing system controlled adult NSC self-renewal and differentiation in a dose-dependent manner, while the cell-engaging lam-IKVAV(19) ligand only had modest effects on differentiation. The combination of both defined media and substrate conditions in the IPN culture system represents a highly tunable platform to probe stem cell signal transduction mechanisms and to control stem cell behavior in vitro.

Three characterization methods were used to analyze the IPN chemical and mechanical properties: XPS, fluorescently-tagged ligands, and quartz crystal microbalance with dissipation monitoring (QCM-D).
After each step of synthesis, XPS peak intensity ratios (i.e., $\mathrm{O} / \mathrm{N}$ and $\mathrm{C} / \mathrm{N}$ ) indicated that the IPN coated the poly(styrene) substrate, while angle-resolved studies demonstrated that the pAAm and p(EG-co-AAc) networks were interpenetrating as previously described. ${ }^{16}$ IPN physical properties, specifically thickness as well as storage and loss moduli, were measured by modeling QCM-D frequency and dissipation changes upon swelling of the IPN in DPBS ${ }^{17}$ (Table I). Upon exposure to DPBS, the IPN swelled within seconds to $\sim 12 \mathrm{~nm}$ and was nonfouling (i.e., low protein adsorption) to media components $\left(<5 \mathrm{ng} / \mathrm{cm}^{2}\right.$ adsorbed protein). ${ }^{17}$ FITC-labeled peptides were used in several IPN preparations to determine the surface density of bioactive peptides as a function of the amount of soluble peptide added to the surface conjugation reaction (data not shown), which allowed subsequent fine-tuning of peptide surface density in the $1-20 \mathrm{pmol} / \mathrm{cm}^{2}$ range. The tether length of $\sim 3 \mathrm{~nm}$ between the IPN and any selected bioactive signal was specifically chosen to present the signal away from the IPN and thereby enhance cell engagement. ${ }^{20}$ Therefore, the peptide-modified IPN ligand density $\left(1.2-21 \mathrm{pmol} / \mathrm{cm}^{2}\right)$, hydrated thickness $(14 \mathrm{~nm})$, swelling behavior (polymer volume fraction, $\left.v_{2 \mathrm{~s}}=0.42\right)$, shear modulus $\left(\left|G^{*}\right|=94 \mathrm{kPa}\right)$, and nonfouling properties define a specific cellular microenvironment, namely by specifying the dose and mechanical context of the chemical signals presented to stem cells (see Table I).

A variety of ECM proteins, such as fibronectin, laminin, vitronectin, thrombospondin, tenascin, and collagen IV, may engage NSCs in the brain. ${ }^{21}$ Although

TABLE I

Defined Neural Stem Cell Culture Conditions

\begin{tabular}{lc}
\hline Substrate properties & $11 \mathrm{kPa}$ \\
Shear modulus & $93 \mathrm{kPa}$ \\
Loss modulus & $14 \mathrm{~nm}$ \\
Hydrated thickness & 0.42 \\
Polymer volume fraction & \\
Solid phase signals & $5.3 \mathrm{pmol} / \mathrm{cm}^{2}$ \\
RGD peptide motif & $1.17 \mathrm{nM}$ \\
Proliferation factors & \\
bFGF (rat) [recombinantly made] & $0.001 \mathrm{mM}$ \\
Differentiation factors & $0.005 \mathrm{mM}$ \\
Retinoic acid & \\
Forskolin & \\
Other components & \\
D-MEM/F-12 & \\
N-2 components & \\
$\quad$ Human transferrin (Holo) & \\
$\quad$ [recombinantly made] & $0.01 \mathrm{mM}$ \\
$\quad$ Insulin (Bovine) [recombinantly made] & $0.01 \mathrm{mM}$ \\
$\quad$ Progesterone & $0.01 \mathrm{mM}$ \\
$\quad$ Putrescine & $0.01 \mathrm{mM}$ \\
$\quad$ Selenite & $0.01 \mathrm{mM}$ \\
\hline
\end{tabular}

The mechanical and chemical environmental signals presented to neural stem cells in our engineered microenvironment are all quantitatively summarized here. 
many integrin receptors (e.g., $\alpha_{5} \beta_{1}, \alpha_{8} \beta_{1}, \alpha_{\mathrm{IIb}} \beta_{3}, \alpha_{\mathrm{v}} \beta_{3}$, $\alpha_{v} \beta_{5}, \alpha_{v} \beta_{6}$, and $\left.\alpha_{v} \beta_{8}\right)$ can recognize a RGD motif, amino acids flanking the RGD were chosen to increase the specificity from that of the RGD motif in laminin, which can target several integrin receptors including $\alpha_{v} \beta_{3}{ }^{23}$ and $\alpha_{6} \beta_{1}{ }^{24}$ to that of the RGD motif in bone sialoprotein, which targets more specifically integrin receptors $\alpha_{v} \beta_{3}$ and $\alpha_{2} \beta_{1}$ with high affinity. ${ }^{25}$ NSCs isolated from the adult hippocampus, ${ }^{8}$ found to express $\beta_{3}$ integrins (data not shown), were seeded onto bspRGD(15)-modified IPNs at cell densities varying over four orders of magnitude. Under proliferating media conditions, cell adhesion and morphology on the RGD surfaces were similar to that on laminin [Fig. $1(b, c)]$. By contrast, on surfaces with either low or no bsp-RGD(15), cells did not adhere effectively [Fig. $1(\mathrm{~d}, \mathrm{e})]$ and resembled NSC growth in suspension as neurospheres. ${ }^{26}$ Such spheres provide less precise control over the cellular microenvironment, due in part to spatial gradients in signaling and nutrients and internal necrosis. The bsp-RGE(15), which differs from the bsp-RGD(15) peptide by only a methylene group, did not support attachment and thus highlighted the specificity of the NSC engagement with the peptide-modified IPN. Importantly, the bspRGD(15)-modified IPN also supported NSC proliferation in a ligand dose-dependent fashion, and IPNs with the highest bsp-RGD(15) density supported faster cell proliferation than standard laminin-coated surfaces [Fig. 1(f)]. Any increase in cell number on the negative control bsp-RGE(15)-modified IPNs reflected growth of weakly adherent neurospheres [Fig. 1(e,f)]. A surface density between 5.3 and $11 \mathrm{pmol} / \mathrm{cm}^{2} \mathrm{bsp}-$ RGD(15) was needed to support both proliferation and differentiation of NSCs (see below), corresponding to $\sim 10^{6}$ ligands per cell for the $10 \mu \mathrm{m}$ diameter cells.

In addition to precise control of cell proliferation, the bsp-RGD(15)-modified IPNs supported multipotent NSCs in several states of differentiation. Similar levels of mRNA encoding nestin, a neurofilament characteristic of immature neural cells, ${ }^{27}$ were observed on bspRGD(15)-modified IPNs and laminin surfaces for all time points analyzed up to 14 days in bFGF (i.e. proliferating conditions $)^{10}$ [Fig. 2(a)]. Subsequently, cells were subjected to differentiation conditions (i.e. retinoic acid and forskolin). ${ }^{10}$ Cell morphology as well as immunostaining of lineage-specific markers were similar on laminin versus bsp-RGD(15)-modified IPN surfaces [Fig. 2(b-d), left]. Furthermore, qRT-PCR for lineage specific markers indicated that the laminin and bsp-RGD(15)-modified IPN surfaces supported differentiation into neural lineages to the same extent [Fig. 2(c,d), right].

We next examined whether cell differentiation depended on RGD density, as found previously for cell proliferation (Fig. 1). The ability of the surfaces to support differentiation decreased with reducing RGD density [Fig. 3(a,b)]. Further work is necessary to determine whether signaling by $\alpha_{v} \beta_{3}$ or other integrins actively contributes to cell differentiation, a potentially important result for adult neurogenesis given that the expression of both bone sialoprotein protein and $\alpha_{\mathrm{v}} \beta_{3}$ integrin are upregulated at sites of central nervous system injury. ${ }^{28}$ In addition, our results showing NSC engagement with $\alpha_{v} \beta_{3}$ integrin ligands suggest roles in adult neurogenesis for specific ECM isoforms that act as strong ligands for $\alpha_{v} \beta_{3}$ integrins (e.g., isoforms with laminin $\alpha 5$ chains $^{29}$ ).

These data indicate that a synthetic hydrogel presenting a simple RGD-containing motif functionally replaced the ability of laminin-1 to support cell attachment, proliferation, and differentiation, a significant result considering that complex ECM molecules such as laminin are extremely large $(850 \mathrm{kDa})$ and contain a number of cell-binding motifs. ${ }^{11-13}$ We next tested whether another laminin motif, Ile-Lys-Val-Ala-Val [lam-IKVAV(19)], putatively involved in neurite extension of mature neurons ${ }^{12,13}$ and differentiation of fetal neuronal progenitors, ${ }^{14}$ could modulate cell behavior. We took advantage of the fact that the highly modular synthetic IPN matrix could be conjugated with diverse combinations of biochemical signals, such as lam-IKVAV(19) and bsp-RGD(15) peptides at various ratios (i.e., creation of binary peptide phase diagrams). We observed that lam-IKVAV(19) neither enhanced cell proliferation nor differentiation [Fig. 3(b,c)]. On pure lam-IKVAV(19)-modified IPNs, NSCs did not adhere under differentiating or proliferating media conditions, similar to behavior on the negative control RGE surface [Figs. 1(e) and 3(a-c)]. Furthermore, cell differentiation into both neuronal and astrocytic lineages progressively decreased as the IKVAV/RGD ratio increased [Fig. 3(a,b)]. These results further confirm that the RGD peptide-modified IPN, without introducing any cooperative effects from mechanisms involving lam-IKVAV(19), was able to functionally substitute for laminin in early differentiation stages of adult NSCs. Furthermore, in contrast to fetal neuronal progenitors ${ }^{14}$ or mature neurons, ${ }^{12,13}$ IKVAV did not support the attachment, neuronal differentiation, or neurite extension of adult NSCs at the surface densities tested.

The extent to which the peptide-modified IPN microenvironment either selects for cells that have adopted a particular behavior or actively instructs cells towards specific behaviors requires further characterization. For proliferating media conditions, poorly adhered or necrotic cells were not observed at any time, and thus the IPN microenvironment likely instructs cells to survive and proliferate. The IPN microenvironment could affect stem cell signal transduction via a variety of mechanisms, including ones involving stretch-induced ion channels, lipid bilayers, 


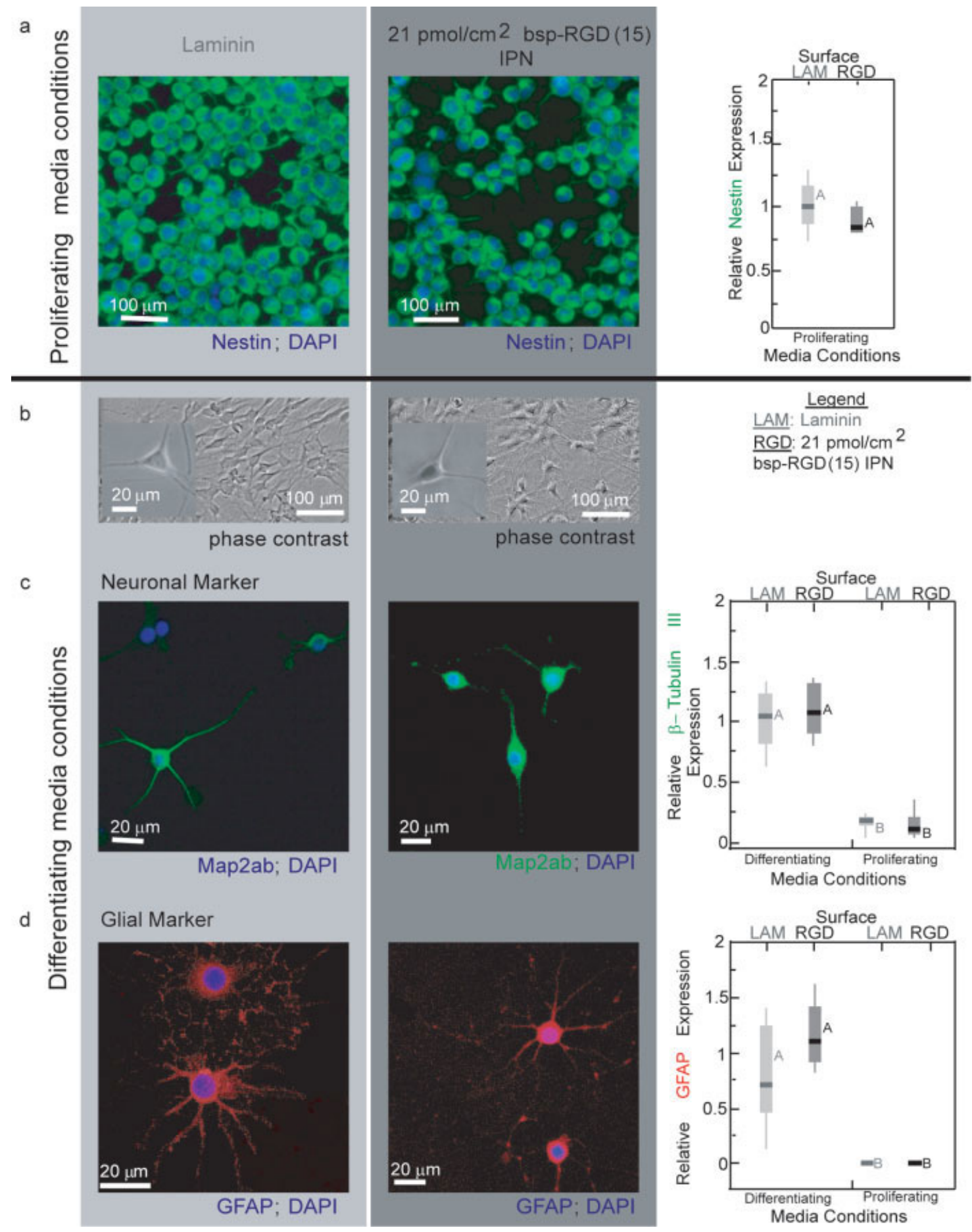

Figure 2. Cell phenotype of immature and differentiated cells on synthetic RGD-modified IPNs. (a) Immunofluorescent staining for the immature neuronal stem cell marker nestin (green) in cells proliferating on laminin or $21 \mathrm{pmol} / \mathrm{cm}^{2} \mathrm{bsp}-$ RGD(15)-modified IPNs (media conditions: $1.2 \mathrm{n} M$ basic fibroblast growth factor). In all stained images, cell nuclei were stained with SYBR Green or DAPI (blue). Gray and black represent laminin and bsp-RGD(15), respectively, throughout the figure. (b) Phase-contrast images of neural stem cells on laminin or $21 \mathrm{pmol} / \mathrm{cm}^{2}$ RGD-modified IPNs during neuronal differentiation (media conditions: $1 \mu M$ retinoic acid with $5 \mu M$ forskolin for 6 days); Cellular staining for (c) the early neuronal marker microtubule associated protein 2ab (Map2ab, green) and (d) the mature glial marker glial fibrillary acidic protein (GFAP, red) on laminin or $21 \mathrm{pmol} / \mathrm{cm}^{2} \mathrm{RGD}$ modified IPNs during differentiation. Right-hand panels compare gene expression levels as measured by qRT-PCR during proliferation and differentiation for lineage markers: nestin, $\beta$ tubulin III, and GFAP. The box plots summarize the distribution of points, where the thick line signifies the median and the top and bottom ends of the box delineate the 25th and 75th quartiles. Within each plot, levels not connected by same letter (A, B) are significantly different $(p<0.05$; ANOVA between groups with Tukey-Kramer Honestly Significant Difference post hoc test). 
a Differentiating Media Conditions: $1 \mu \mathrm{M}$ Retinoic Acid, $5 \mu \mathrm{M}$ Forskolin; 6 days

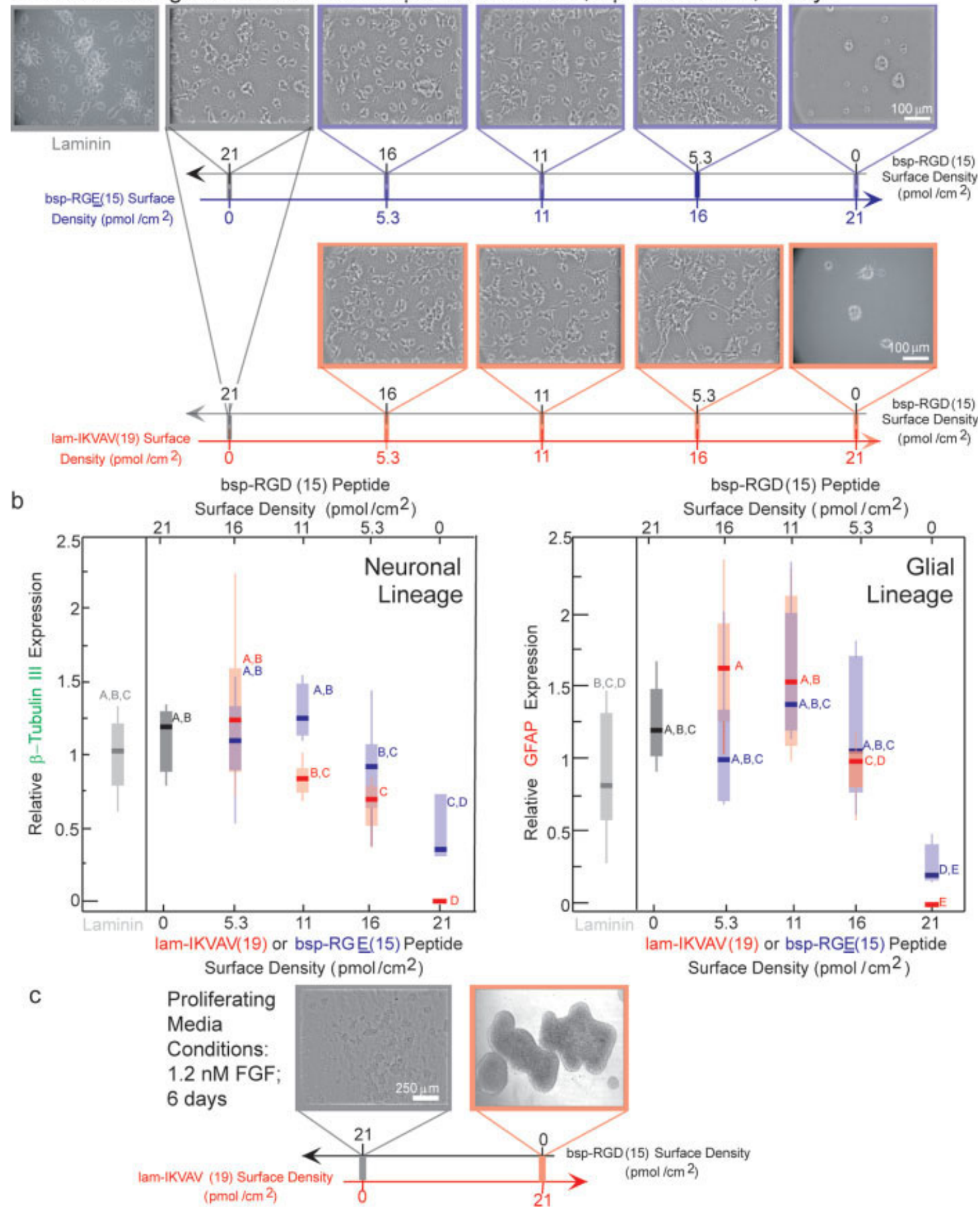

Figure 3. In mixed peptide IPNs, bsp-RGD(15) peptide surface density controls phenotype. (a) Phase-contrast images of NSCs after 6 days in culture on IPNs with mixed peptide conjugation in differentiating (1 $\mu M$ retinoic acid, $5 \mu M$ forskolin) media conditions. Surface density of peptide mixtures correspond to abscissa values directly below for bsp-RGD(15) plus lam-IKVAV(19) or bsp-RGE(15). Gray, black, red, and blue represent laminin, bsp-RGD(15), lam-IKVAV(19), and bspRGE(15), respectively, throughout the figure. (b) Gene expression of early lineage neuronal marker, $\beta$-Tubulin III, and glial marker, glial fibrillary acidic protein (GFAP), in NSCs grown in differentiation media conditions. Gene expression levels correspond to normalized mRNA abundance as assayed by qRT-PCR after 6 days. The box plots summarize the distribution of points, where the thick line signifies the median and the top and bottom ends of the box delineate the 25th and 75th quartiles. Within each plot, levels not connected by same letter (A, B, C, D) are significantly different $(p<0.05$; ANOVA between groups with Tukey-Kramer Honestly Significant Difference post hoc test). (c) Phase-contrast images of NSCs after 6 days in culture on IPNs with $21 \mathrm{pmol} / \mathrm{cm}^{2}$ bsp-RGD(15) or lam-IKVAV(19) peptide conjugation in proliferating (1.2 $\mathrm{nM}$ basic fibroblast growth factor) media conditions. 
intracellular cytoskeleton-associated proteins, and/or cell-surface adhesion receptors. ${ }^{30}$ We have found similar temporal activation of intracellular signaling pathways in NSCs on both bsp-RGD(15) IPNs and laminin (data not shown), indicating that the RGD peptide likely actively signals through integrin receptors. However, further characterization may reveal which specific peptide receptors are activated. Under differentiating media conditions, a small fraction of poorly adhered cells were seen after 2-6 days following NSC seeding on both laminin and IPN surfaces. Adhesion and apoptosis assays with various peptide-modified IPNs in combination with signal transduction agonists/antagonists would shed light on cell interactions with the IPN during this process.

This work defined a systematic engineering approach to designing a combination of bioactive synthetic materials and media conditions to direct stem cell behavior (Table I). Defined cell culture environments can enhance both basic and applied stem cell endeavors. Specifically, several nonlinear synergies between growth factor and substrate signals have been observed in differentiated cell lines. ${ }^{31,32}$ The IPN synthetic approach can readily facilitate the dissection of bioactive motifs within the ECM or other signaling molecules (e.g., Fig. 3), since the modular nature of the synthesis and bioconjugation offers easy exploration of numerous signals that could promote selfrenewal, differentiation, or other cell behavior such as cell migration. Almost every entry in Table I can be adjusted independently to define which combinations of soluble and solid-phase signals control cell behavior. Moreover, substrate compliance ${ }^{33}$ and degradation $^{34}$ can influence cell morphology under proliferation and differentiation conditions, causing drastic changes in stem cell behavior. ${ }^{35}$ The mechanical properties of the IPN can be modulated for exploring the effects of matrix mechanics on cell signaling and behavior. Lastly, for regenerative medicine applications, the matrix could enhance cell survival and grafting after implantation at the site of disease or injury; however, there are still significant obstacles in translating in vitro results on biomaterial performance to clinically relevant implantable materials, even for materials that show promise in vivo. ${ }^{14,36}$ These efforts may be assisted by using in vitro IPNs as an intermediate platform to devise design rules for neural implants, particularly chemistries that can be readily expanded to make cell-responsive (e.g., protease degradable) matrices. ${ }^{37}$ In summary, the bioactive IPN presents a precise, tunable microenvironment to control the proliferation and differentiation of stem cells, which can be rationally harnessed for basic scientific, bioprocess, and therapeutic purposes.

The authors would like to thank S. Agrawal, M. Robertson, G. Harbers, and M. Gilbert for technical assistance, advice, and discussions.

\section{References}

1. Lindvall O, Kokaia Z, Martinez-Serrano A. Stem cell therapy for human neurodegenerative disorders-how to make it work. Nat Med 2004;10:(Suppl)S42-S50.

2. Proceed with caution (Editorial). Nat Biotechnol 2005;23: 763.

3. Sotiropoulou PA, Perez SA, Salagianni M, Baxevanis CN, Papamichail M. Response to the Letter to the Editor by Dr. Dimarakis et al., "Cell culture medium composition and translational adult bone marrow-derived stem cell research." Stem Cells 2006;24:1409-1410.

4. Sotiropoulou PA, Perez SA, Salagianni M, Baxevanis CN, Papamichail M. Characterization of the optimal culture conditions for clinical scale production of human mesenchymal stem cells. Stem Cells 2006;24:462-471.

5. Li Y, Powell S, Brunette E, Lebkowski J, Mandalam R. Expansion of human embryonic stem cells in defined serum-free medium devoid of animal-derived products. Biotechnol Bioeng 2005;91:688-698.

6. Svendsen CN, Langston JW. Stem cells for Parkinson disease and ALS: Replacement or protection? Nat Med 2004;10:224, 225.

7. O'Neill A, Schaffer DV. The biology and engineering of stem cell control. Biotechnol Appl Biochem 2004;40:(Part 1)5-16.

8. Lai K, Kaspar BK, Gage FH, Schaffer DV. Sonic hedgehog regulates adult neural progenitor proliferation in vitro and in vivo. Nat Neurosci 2003;6:21-27.

9. Campos LS. $\beta 1$ integrins and neural stem cells: Making sense of the extracellular environment. Bioessays 2005;27: 698-707.

10. Palmer TD, Ray J, Gage FH. FGF-2-responsive neuronal progenitors reside in proliferative and quiescent regions of the adult rodent brain. Mol Cell Neurosci 1995;6:474-486.

11. Powell SK, Kleinman HK. Neuronal laminins and their cellular receptors. Int J Biochem Cell Biol 1997;29:401-414.

12. Bellamkonda R, Ranieri JP, Aebischer P. Laminin oligopeptide derivatized agarose gels allow three-dimensional neurite extension in vitro. J Neurosci Res 1995;41:501-509.

13. Tashiro K, Sephel GC, Weeks B, Sasaki M, Martin GR, Kleinman HK, Yamada Y. A synthetic peptide containing the IKVAV sequence from the A chain of laminin mediates cell attachment, migration, and neurite outgrowth. J Biol Chem 1989;264:16174-16182.

14. Silva GA, Czeisler C, Niece KL, Beniash E, Harrington DA, Kessler JA, Stupp SI. Selective differentiation of neural progenitor cells by high-epitope density nanofibers. Science 2004;303: 1352-1355.

15. Harbers GM, Healy KE. The effect of ligand type and density on osteoblast adhesion, proliferation, and matrix mineralization. J Biomed Mater Res A 2005;75:855-869.

16. Harbers GM, Gamble LJ, Irwin EF, Castner DG, Healy KE. Development and characterization of a high-throughput system for assessing cell-surface receptor-ligand engagement. Langmuir 2005;21:8374-8384.

17. Irwin EF, Ho JE, Kane SR, Healy KE. Analysis of interpenetrating polymer networks via quartz crystal microbalance with dissipation monitoring. Langmuir 2005;21:5529-5536.

18. Barber TA, Harbers GM, Park S, Gilbert M, Healy KE. Ligand density characterization of peptide-modified biomaterials. Biomaterials 2005;26:6897-6905.

19. Abranches E, O'Neill A, Robertson MJ, Schaffer DV, Cabral JM. Development of quantitative PCR methods to analyse neural progenitor cell culture state. Biotechnol Appl Biochem 2006;44:(Part 1)1-8.

20. Bearinger JP, Castner DG, Healy KE. Biomolecular modification of $\mathrm{p}$ (AAm-co-EG/AA) IPNs supports osteoblast adhesion and phenotypic expression. J Biomater Sci Polym Ed 1998; 9:629-652. 
21. Venstrom KA, Reichardt LF. Extracellular matrix. 2: Role of extracellular matrix molecules and their receptors in the nervous system. The FASEB Journal 1993;7:996-1003.

22. Takagi J Structural basis for ligand recognition by RGD (ArgGly-Asp)-dependent integrins. Biochem Soc Trans 2004;32: (Part 3)403-406.

23. Pfaff $\mathrm{M}$, Gohring W, Brown JC, Timpl R. Binding of purified collagen receptors $(\alpha 1 \beta 1, \alpha 2 \beta 1)$ and RGD-dependent integrins to laminins and laminin fragments. Eur J Biochem 1994;225: 975-984.

24. Tashiro K, Sephel GC, Greatorex D, Sasaki M, Shirashi N, Martin GR, Kleinman HK, Yamada Y. The RGD containing site of the mouse laminin A chain is active for cell attachment, spreading, migration and neurite outgrowth. J Cell Physiol 1991;146:451-459.

25. Rezania A, Healy KE. Integrin subunits responsible for adhesion of human osteoblast-like cells to biomimetic peptide surfaces. J Orthop Res 1999;17:615-623.

26. Sen A, Kallos MS, Behie LA. Passaging protocols for mammalian neural stem cells in suspension bioreactors. Biotechnol Prog 2002;18:337-345.

27. Lendahl $U$, Zimmerman LB, McKay RD. CNS stem cells express a new class of intermediate filament protein. Cell 1990;60:585-595.

28. Meller R, Stevens SL, Minami M, Cameron JA, King S, Rosenzweig H, Doyle K, Lessov NS, Simon RP, Stenzel-Poore MP. Neuroprotection by osteopontin in stroke. J Cereb Blood Flow Metab 2005;25:217-225.
29. Sasaki T, Timpl R. Domain IVa of laminin a5 chain is cell-adhesive and binds $\beta 1$ and $\alpha \mathrm{V} \beta 3$ integrins through Arg-GlyAsp. FEBS Lett 2001;509:181-185.

30. Alenghat FJ, Ingber DE. Mechanotransduction: All signals point to cytoskeleton, matrix, and integrins (Review). Sci STKE 2002;2002:PE6.

31. Yamada KM, Even-Ram S. Integrin regulation of growth factor receptors. Nat Cell Biol 2002;4:E75-E76.

32. Decker L, Baron W, Ffrench-Constant C. Lipid rafts: Microenvironments for integrin-growth factor interactions in neural development. Biochem Soc Trans 2004;32:426-430.

33. Engler A, Bacakova L, Newman C, Hategan A, Griffin M, Discher D. Substrate compliance versus ligand density in cell on gel responses. Biophys J 2004;86:617-628.

34. Lee KY, Mooney DJ. Hydrogels for tissue engineering. Chem Rev 2001;101:1869-1879.

35. McBeath R, Pirone DM, Nelson CM, Bhadriraju K, Chen CS. Cell shape, cytoskeletal tension, and RhoA regulate stem cell lineage commitment. Dev Cell 2004;6:483-495.

36. Teng YD, Lavik EB, Qu X, Park KI, Ourednik J, Zurakowski D, Langer R, Snyder EY. Functional recovery following traumatic spinal cord injury mediated by a unique polymer scaffold seeded with neural stem cells. Proc Natl Acad Sci USA 2002; 99:3024-3029.

37. Kim S, Healy KE. Synthesis and characterization of injectable poly $n$-isopropylacrylamide-co-acrylic acid) hydrogels with proteolytically degradable cross-links. Biomacromolecules 2003;4: $1214-1223$. 